\title{
Methodology for User-Centered Innovation in Industrial Living Lab
}

\author{
Angelo Corallo, ${ }^{1}$ Maria Elena Latino, ${ }^{1}$ and Grazia Neglia ${ }^{2}$ \\ ${ }^{1}$ Dipartimento di Ingegneria dell'Innovazione, Università del Salento, Campus Ecotekne, 73100 Lecce, Italy \\ ${ }^{2}$ EKA S.r.l., Via Monteroni s.n., C/O Edificio IBIL, 73100 Lecce, Italy
}

Correspondence should be addressed to Angelo Corallo; angelo.corallo@unisalento.it and Maria Elena Latino; mariaelena.latino@unisalento.it

Received 30 September 2013; Accepted 4 November 2013

Academic Editors: B. C. Cheung, F. Malek, and J. M. Merigo

Copyright (C) 2013 Angelo Corallo et al. This is an open access article distributed under the Creative Commons Attribution License, which permits unrestricted use, distribution, and reproduction in any medium, provided the original work is properly cited.

In the last years the Living Labs (LLs) approach is becoming really important to test new products/services in real-life settings. Following the perspective of user-centered innovation emerged by the critical review of the existing international LLs' methodologies, this paper describes how, in the Living Lab related to KHIRA research project, research activities and innovation are integrated, according to a public-private-person partnership (PPPP), to develop innovation processes, participated and usercentered, in the industrial sector. The LL related to KHIRA research project involves several users categories: industrial partners, universities and research centers, SMEs belonging to Apulian manufacturing industry, public administrations, and other users. A heterogeneous users' community can produce new ideas of products and services oriented to solve real industrial problems as those related to the product life-cycle management (PLM) in complex manufacturing environments. Purpose of this study is to present a methodology that can be used in the industrial LLs aimed at developing new products/services in complex environments, bridging the existing gap between the LLs' activities management and those aimed to develop user-centered innovation.

\section{Introduction}

Technological and methodological development, occurred in the last decade, has led the value chain of companies to present themselves in new networked models (value network). It follows that stakeholders have access to new methodological and technological paradigms that allow them to participate in these value networks and trigger the process of cocreation of products and services [1]. Although the benefits of working in a network are demonstrated [2], often a series of problems occurs, preventing the production of successful business cases [3]:

(i) SMEs' tendency to integrate themselves vertically, in order to share complementary expertise;

(ii) lack of models and tools to identify and validate business opportunities;

(iii) low management of intellectual property rights;

(iv) low level of collaboration among the staffs belongs to different companies (know-how loss); (v) low level of knowledge access;

(vi) low integration of users in the development process of new products/services.

The possibility to overcome these limits is offered by the Living Labs approach. The LLs operate according to the development model open innovation functional region, offering the possibility of bridging the gap between industries and users, thanks to the engagement of end-users in the development process of new products/services [3].

The European Network of Living Labs (ENoLL) defines them as "open innovation environments, operating in reallife settings, where the active engagement of end-users allows the creation of paths of cocreation of new services, products, and social infrastructures" [4].

So, the involvement of users/consumers/citizens in the innovation system developed by a LL leads to the development of a great deal of ideas, knowledge, and experiences and greatly increases the capacity of innovation of all parties involved in the LL [5]. Therefore, it enables the 
cross-fertilization, the possibility to catalyze the innovation process itself, thanks to the collaboration among people from different backgrounds, with different perspectives and knowledge [6].

Following the perspective of user-centered innovation described above, a Living Lab was established within the University of Salento related to Research Project called KHIRA (Knowledge based Holistic Integrated Research Approach Living Lab), in order to create a collaborative space for open innovation processes, participated and user-centered, in which research and innovation activities are integrated, according to a public-private-person partnership (PPPP) aiming to develop innovation in the industrial sector. The presence in the LL of several users' categories allows to see innovation of product/service from different points of view and leads to the creation of a large number of ideas [7] that, if properly selected, can lead to the development of products and services really useful for the potential market. Users engagement in a trial environment of products and services allows the validation of them, providing important feedback that enables to understand if what has been developed will be able to meet the real needs of users involved [8].

The establishment of this LL has seen, during the planning stage, the need to adopt a methodology useful for the holistic management of the activities carried out. The analysis of the literature has seen the presence of several methodologies used in different LLs, but none of them is useful to both LLs' activities management and those aimed to develop usercentered innovation. Therefore, this work intends to present a methodology that can bridge the gap highlighted, providing a useful tool that can be used in the industrial LL aimed at developing new products/services. Hereafter the Living Lab related to the KHIRA research project will be indicated as KHIRA LL.

\section{Research Design}

2.1. Research Context. This research activity has been conducted within the Collaborative Product Design Management (cPDM) Laboratory of the Centro Cultura Innovativa d'Impresa (University of Salento). The laboratory's purpose is to support companies operating in the product design and development field, to orient the research activity to new perspectives and scientific findings. In the CPDM Laboratory about 60 researchers are employed; among them there are professors, fellows, senior and young researchers, and Ph.D. students.

The Laboratory focuses its research activities on complex products such as automotive, naval, and aerospace, proposing technological solutions to improve firms' practices. The groups operating in the laboratory focus on several research fields: simulation methodologies and data management, automation, product life cycle management (PLM), knowledge security, business process management, service engineering, energy and additive manufacturing, social network, and impact analysis. These groups are also involved in several regional, national, and European projects with academic and industrial partners, such as KHIRA Research Project. The main objective of this Research Project is the creation of

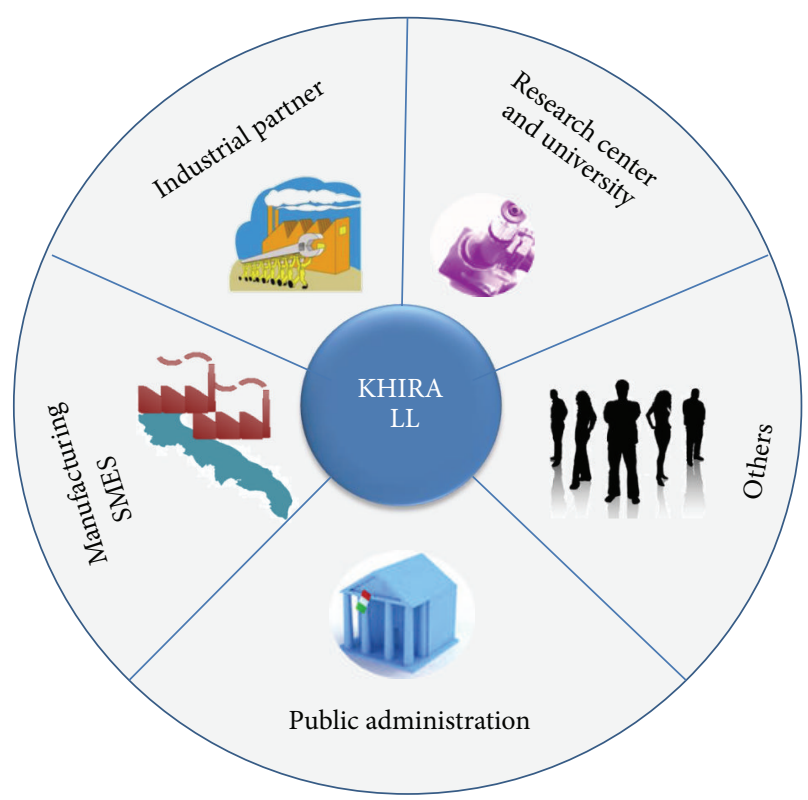

FIGURE 1: KHIRA LL user's categories.

a technological platform, a methodological framework and expertise related to the product life-cycle, in a space where open, participatory and user-centered innovation processes are developed, integrating research and innovation activities in a public-private logic.

So that, the KHIRA LL was established by the CPDM Laboratory: it is a collaborative space aiming to create user-centered innovation, based on research and innovation activities in the industrial field. The KHIRA LL is composed by users coming from different sectors: industrial partners that collaborate with cPDM Laboratory in several research projects; researchers from universities and research centers, such as: University of Salento, cPDM, and so on; small medium enterprises (SMEs) belonging to the Apulian manufacturing industry; public administrations and other actors that can be, directly or indirectly, interested in the KHIRA LL. In Figure 1 users' categories are shown.

In particular, industrial partners are considered the first and potential customers of the product/service developed in the LL's trial downstream. Their presence in the LL will ensure the development of solutions that solve real industrial problems with particular reference to problems related to the product life cycle management in complex manufacturing environments, according to the logic of holistic engineering. The involvement of the Apulian manufacturing SMEs in the LL will allow to start test processes of the developed innovations in order to improve them. Due to the strong LL's tendency to develop innovation in the Apulia region, it is believed that the presence of territorial government users can facilitate the promotion of the local activities, also ensuring the support in financial planning. In the category "others," it was considered to put together which people who do not belong to the previous categories, but that may potentially be interested in the activities carried out under KHIRA LL, such as freelancers, public organizations, and districts. 
Currently, KHIRA LL is in the planning stage; it has three industrial partners, two universities, and five users (e.g., districts and industrial organizations) belonging to the category "others."

2.2. Research Problem and Method. In order to create a successful LL and develop a really useful innovation for users community, it is essential to adopt a methodology to manage the LL in all its aspects. The starting community of the Living Lab has defined the KHIRA LL's mission: "Developing usercentered innovation in the PLM field starting from the ideas and skills coming from several classes of users."

It follows that the main objective of the KHIRA LL is the development of user-centered innovation, but it is impossible to do so without several activities oriented to the LL management. Several methodologies used for the Living Lab management are available, but there is not a unique method that satisfies all the necessities emerged in the KHIRA LL. From a critical review of the Living Lab's methodology emerges that some methodologies focused on innovation development not providing any strategy to create and manage a community. On the contrary, other methodologies focused on management aspects not providing any strategy to develop user-centered innovation. To address the research topic, the collaboration among the KHIRA LL's starting community had a central role to overcome the limits of a single researcher's work, permitting the analysis of the matter from a different point of view. This also allowed to create a first sense of belonging to the community and achieving results shared among users. The research design is composed by three main phases: starting phase, analysis phase, and elaboration phase, as it is a good practice in cPDM [9]. During the starting phase the LL's mission has been specified; this has enabled to identify the operating environment and the goals of the KHIRA LL. Outputs of this phase are requirements that methodology should meet:

R1: the methodology should include a process oriented to the development of user-centered innovation.

R2: the methodology should include a process oriented to the LL's background planning.

R3: the methodology should include a process oriented to create the LL's community.

R4: the methodology should include a process oriented to manage the LL's community.

R5: the methodology should include a process oriented to the future commercialization of product/service developed in the LL.

In the starting phase, the tools used are face-to-face meetings, questionnaires, interviews, and blogs. In the analysis phase, the literature about the Living Lab methodology has been examined in order to identify if a particular methodology can satisfy the requirements mentioned above. From this phase, the results of the analysed methodology cover part of them. The tools used in this stage are face-toface meetings and blogs. In the elaboration phase, the last one, a new methodology has been developed using tools such as blogs, focus groups, and face-to-face meetings.

\section{Critical Review of Living Labs Methodologies}

This section will provide a critical review of the literature relating to the Living Lab methodologies resulted from the analysis phase of the design research, in order to investigate a useful methodology to coordinate the activities carried out in the KHIRA LL.

3.1. FormIT Methodology. FormIT methodology was developed by Ståhlbröst and Holst [10] in order to support the activities of the Botnia LL. "The FormIT process can be seen as a spiral in which the focus and shape of the design become cleaner, while the attention of the evaluation broadens from a focus on concepts and usability aspects to a holistic view on the use of the system." The methodology includes three iterative cycles through which innovation is generated:

(1) concept design cycle;

(2) prototype design cycle;

(3) innovation design cycle.

Before and after these, there are two additional cycles: planning and commercialization. Each cycle has three stages: Appreciate opportunities, Design, and Evaluate.

The interaction with users is a prerequisite of the FormIT methodology in every cycle. The basic idea is to increase knowledge through iterative interaction among stages and people with different perspectives (usability, business, and technology). The FormIT methodology can be seen as a spiral in which purpose and design of the product/service evolve over time and become increasingly clear and defined. Also the evaluation of the product/service sees different evolutions moving from one cycle to another, as described below.

Planning is important to define the limit of the project, identify the skills required in order to facilitate the knowledge sharing, and increase vision understanding of the stakeholders involved.

Cycle 1: concept design focuses on the discovery of new opportunities and the definition of the basic needs that different stakeholders have in relation to a product or service and ends with the definition of a concept which represents those needs. In this stage, the purpose of innovation, user groups, and their characteristics and role in the innovation process are analysed; then the information is translated into a concept. The purpose of this evaluation is also to give the users the opportunity to cocreate the concept in accordance with their own needs.

Cycle 2: prototype design starts with the identification of the stakeholders' needs regarding the use of the concept developed. It is necessary to collect a series of data through interviews and observations about each functionality of the product/service. This allows realizing the design of the first prototype of a product/service. The prototype has to be sufficiently detailed, so the users should be able to perceive and experience how the final product will be. The evaluation is focused on the aspects of usability.

Cycle 3: innovation design starts analysing the results of usability able to generate changes in needs and innovation. 
Small changes of the needs are almost common, especially gradually the users understand structure, contents, workflows, and interfaces of the product/service. Based on changing needs, it is possible to modify the innovation design. The last stage of evaluation is the user experience, the results of which should be positive or negative.

Commercialization can appear as a separate stage in which the purpose is the evaluation of the potential market and the introduction of innovation to potential buyers [10].

3.2. Service Experience Engineering Methodology. The service experience engineering (SEE) methodology introduced in Taiwan Living Lab to improve the process of open innovation is articulated in three main processes.

Find process focuses on the definition of LL operational context, the observation of users' behaviour and the following data collection, the observation of technologies, and the consequent identification of new ICT trends. The purpose of this stage is the discovery of unexpected use of ICTs and new product/service opportunities through the analysis of needs and problems of users and the analysis of market trends.

InnoNet process focuses on the analysis of business ecosystems and product/service modelling through the survey of the value chain actors, data collected analysis, scouting of the users requirements, gap analysis between demand and services offered, and design of new service models. In this process, public administrations, researchers, industry partners, and consumers are all involved to cocreate new products/services.

Design lab process allows industries to test new services or products in real-life settings through techniques such as proof of concept (PoC), proof of service (PoS) and proof of business (PoB) in which try, respectively, usability, performances and acceptance, business model and marketing strategies. The failure of several new products and services is often not due to a lack of advanced technologies but to an inability to understand the real users' needs [11].

3.3. C@R Methodology. The Collaboration@Rural (C@R) methodology was created to develop and implement collaborative working environments in rural Living Labs. The C@R methodology is articulated into the stages described below.

Construction of the local users' community, composed of stakeholders, firms, politicians, research institutes, and final users, provides the opportunity to generate innovation.

Users engagement is divided into two levels: the first encourages the settlement of strategic stakeholders representing the partners of the LL project and drives the strategic innovation helping to involve the second type of users; the second one is implemented in order to encourage the settlement of users or citizens in the LL [10].

Development of new product/service stage, cyclic and spiral, starts with the creation of user-scenarios and tests limited to simple use cases in order to get quick results and be able to learn together and effectively [10]. The interventions are the identification of users' needs, their analysis, the innovations planning and implementation, and the evaluation of implemented solutions [12].
Network and synergies creation among stakeholders enables interoperability, sharing, and reuse of collaborative services, tools, and developed methods.

Action Research is conducted in collaboration with users, working together, in order to find solutions to everyday reallife problems. This methodology, therefore, does not focus on technology, architecture, and collaboration platforms but on the process of users engagement and test of the Living Labs [12].

3.4. Rural Inclusion Methodology. The rural inclusion methodology (RIM) involves users in all the stages of the innovation process and is composed the following.

Community planning defines LL's mission; objectives, targets, and related evaluation parameters; implementation plan; users' types and skills necessary to the LL; teams to organize the users and the implementation framework; activities to build the community; the sharing of adopted strategy.

Communication strategy setup: if the members of the community feel disconnected, the sense of community is lost. The means of communication should not be fragmented; it is necessary to fix a few clear and accessible means of communication (mailing lists, wikis, and forums). Combining efficiency and simplicity in the LL processes is crucial for their success.

Community management process is articulated in four subprocesses: (1) promotion of the community process, necessary to build a shared vision around the community and communicate enthusiasm; (2) measurement of the community motivation and participation using a set of specific indicators; (3) government of the community using governance policy and communication channels between the governing bodies and users, managing conflicts within the community; (4) events organization in order to engage users and get immediate feedback about the LL activities. These meetings may be real or virtual.

Keeping stakeholders motivated in terms of participation in activities. It is necessary to activate new discussions, answer quickly, communicate objectives in a clear and simple way, recognize the contributions made by users, and ensure that the users have fun [13].

3.5. Summary of the Literature Review. As described previously, the literature review of international Living Lab methodologies has been conducted in order to identify a methodology able to satisfy the requirements proposed by first users in LL's community. Table 1 shows how the methodology analysed satisfies the requirements proposed.

FormIT methodology satisfies three requirements: (1) it includes a set of processes oriented to the developed usercentered innovation composed of concept design, prototype design, and innovation design that in a cyclical manner transform an idea of innovation in an innovative product/service, (2) it includes a process oriented to the LL's background planning, and (3) it includes a process oriented to commercialization of product/service developed.

SEE methodology satisfies two requirements: (1) it includes a process of InnoNet and design lab oriented to 
TABLE 1: KHIRA LL requirements satisfaction.

\begin{tabular}{|c|c|c|c|c|}
\hline \multirow{2}{*}{ Requirement } & \multicolumn{4}{|c|}{ Methodology } \\
\hline & FormIT & SEE & $\mathrm{C} @ \mathrm{R}$ & RIM \\
\hline $\begin{array}{l}\text { R1: the methodology should include } \\
\text { a process oriented to the } \\
\text { development of user-centered } \\
\text { innovation }\end{array}$ & $\mathrm{X}$ & $\mathrm{X}$ & $\mathrm{X}$ & \\
\hline $\begin{array}{l}\text { R2: the methodology should include } \\
\text { a process oriented to the LL's } \\
\text { background planning }\end{array}$ & $\mathrm{X}$ & $\mathrm{X}$ & $\mathrm{X}$ & \\
\hline $\begin{array}{l}\text { R3: the methodology should include } \\
\text { a process oriented to create the LL's } \\
\text { community }\end{array}$ & & & $\mathrm{X}$ & $\mathrm{X}$ \\
\hline $\begin{array}{l}\text { R4: the methodology should } \\
\text { include a process oriented to } \\
\text { manage the LL's community }\end{array}$ & & & & $\mathrm{X}$ \\
\hline $\begin{array}{l}\text { R5: the methodology should include } \\
\text { a process oriented to future } \\
\text { commercialization of } \\
\text { product/service developed in LL }\end{array}$ & $\mathrm{X}$ & & & \\
\hline
\end{tabular}

developed user-centered innovation and (2) it includes the find process oriented to LL's background planning.

C@R methodology satisfies three requirements: (1) it includes the development of new product/service stage, cyclic and spiral stage, oriented to developed user-centered innovation from several scenarios proposed by users; (2) it includes construction of the local user community process oriented to LL's background planning; (3) it includes user involvement process oriented to create a Living Lab community.

RIM methodology satisfies two requirements: (1) it includes community planned process oriented to LL's background planning; (2) it includes several processes oriented to manage the LL's community, such as communication strategy setup, community management, and keep stakeholders motivated.

\section{KHIRA LL Methodology Proposal}

As underlined in the review, the analysis of international Living Labs methodologies represents a guide for the definition of methodology to orchestrate the KHIRA LL in all its activities, able to drive both the LL management perspective and the user-centered innovation process. The KHIRA LL methodology is illustrated in Figure 2.

The methodology considers three stages: planning, operational, and commercialization stages. At every stage it is possible to find management process (in green color) and innovation development process (in blue color).

4.1. Planning Stage. The planning stage consists of a single process called LL planning. The aim of this process is the description of the Living Lab context, through the definition of

(i) industries which generate innovation;

(ii) product/service class which generates innovation; (iii) LL's mission;

(iv) strategic partners to be involved in the LL;

(v) types of users and their skills;

(vi) how to join the LL;

(vii) plan of activities.

The planning stage is the first phase in the LL implementation. Generally, this phase ends with a promotional event.

4.2. Operational Stage. The operational stage consists of four management processes and two innovation development processes.

Users' engagement is the first management process to be carried out in the operational stage; it is preparatory for the ideas scouting and selection process. The involvement methodology consists of two types of participations: the first is oriented to involve key partners that will collaborate in the LL management; the second is oriented to involve all users belonging to categories identified in the planning stage. These activities can be repeated during the operational stage.

Communication management is a management process within the operational stage. The communication among users is essential for the LL success; in KHIRA LL, it is used as information platform consisting of several tools like wiki, forum, and chat, enabling users to communicate and share information and documents.

Government and conflict management is a management process within the operational stage. Defining a behaviour policy and managing conflicts is very important, because the KHIRA LL community involves many users with different backgrounds. Therefore, this process aims to define the behaviour policy that the users have to follow during collaborative and cocreation activities. The role of moderator was established for monitoring users' behaviour and resolving potential conflicts.

Ideas scouting and selection is an innovation development process starting at the end of users engagement process; it is preliminary to the user-centered innovation process. During this stage all LL's stakeholders can propose new ideas related to products or services. These ideas will be selected and evaluated. For each idea selected, it will be realize a process of developing user-centered innovation.

Developing user-centered innovation is an innovation development process emerged from ideas scouting and input selection. The operational of this process is inspired by FormIT methodology [14]. It is an iterative and spiral process consisting of three subprocesses that can repeat themselves:

(i) concept definition;

(ii) prototype definition;

(iii) product/service definition.

According to FormIT methodology, each subprocess is composed of three activities: (1) users' needs analysis that aims to investigate users' needs, at different levels, in several subprocesses; (2) concept design: prototype and product/service; (3) evaluation activity that aims to identify if the design 


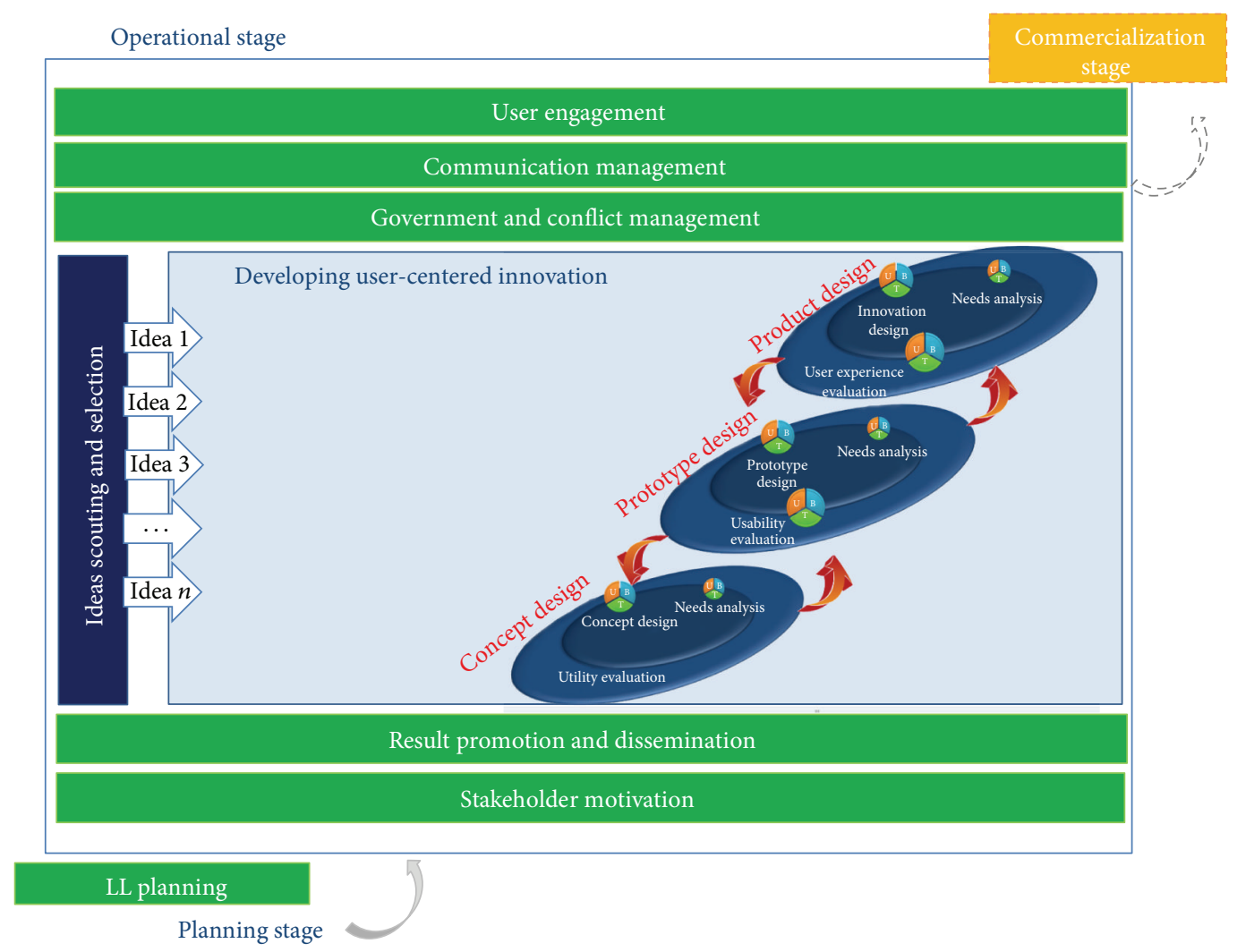

FIGURE 2: KHIRA LL methodology proposal.

corresponds to users' needs. These activities are carried out taking into account three different aspects: usability, business, and technological aspects of the innovation developed.

Concept definition aims to represent the idea and opportunity discovered through a concept. In the design field, concept is a project proposal, essential to define the key elements of a project; it provides the basis for the project implementation [15]. Then, starting from an idea selected by ideas scouting and selection process proceeds to analyse the users' needs about the innovation idea. For example, if the idea is to develop a new application that can solve interoperability problems, it is necessary to investigate about the users' problems in the interoperability field. Users' needs analysis starts with activities data collection, which generally occurs by interviews and brainstorming; then it proceeds analysing the data collected and organizing them on the basis of business requirements [16]. These requirements will be able to describe, clearly, users' needs and, at the same time, to proceed with the business concept design. The concept should be adequately detailed so that the users can fully understand the purpose for which innovation will be developed; in this regard, it may be useful to employ tools that can communicate the concept in a clear and immediate way, such as videos, images, or small demo. Once defined the concept, it is necessary to evaluate it, in order to investigate the utility of innovation that can be developed; users have to answer the following question: "can the developed concept meet the needs expressed?". If the answer to the question is positive the subprocess ends; otherwise, it has to be iterated in its macroactivities.

Prototype definition starts when the users validate the concept developed. Then, a new needs analysis follows, in order to identify user's needs in relation to the individual product/service features to be implemented. Even this stage can be carried out using tools such as interviews and brainstorming sessions. Once the data collection activities end, it will be necessary to formalize and systematize the information collected into functional requirements. It can also be useful to use the technique scenario that, using the modelling language UML and its case diagram, allows identifying the features of a product/service and users interaction with it [16]. When the functional requirements are collected, it is possible to proceed to the design and implementation of a first product/service prototype, which includes the design of the basic functionalities, workflows, and interfaces. This prototype will be evaluated in order to investigate its usability. Users have to answer the following questions: "what is the satisfaction degree using the prototype developed?;" "can the developed prototype meet the expectations?" "can the implemented features meet the needs expressed?". If the responses are positive, the subprocess ends; otherwise, it has to be iterated in its macro-activities.

Product/service definition starts with users' needs analysis that, generally, is carried out jointly with the last macroactivity of the previous process, as it tries to investigate the goodness of the prototype developed, by identifying 
improvements. It is essential to take into account that some needs may emerge when the users approach the first version of the product/service; therefore, it is essential to carry out this analysis in all the subprocesses that lead to the development of user-centered innovation. In fact, small changes in the needs are almost common, especially as the users understand the structure, contents, workflows, and interfaces of the product/service. The new needs expressed and the improvement suggestions will be analysed and formalized in new functional requirements, and then it will be possible to switch to the design and development of the product in all its parts. At this stage, it is essential to define the business model of the product/service in order to identify how to benefit from the commercialization of the product/service, what will be the price that the users intend to pay, what are the terms of use of the product/service, and so forth [17]. The last macroactivity of the subprocess of the product/service definition is the evaluation of the product/service that will be carried out in terms of user experience. In this case users have to answer the following questions: "can the product/service be developed to meet the needs expressed?" and "is the business model developed adequate?". If the responses are positive, the subprocess ends; otherwise, it has to be iterated in its macrotasks.

Results promotion and dissemination is a management process that starts when the process of users' engagement is finished; it lasts for the operational phase of the LL. In this process, in fact, all initiatives carried out within the LL are promoted using different tools, such as

(i) participation in national and international events, workshops and conferences, open days, and trade shows;

(ii) publication in journals;

(iii) events organization;

(iv) enrollment in the main social networks (LinkedIn, YouTube, and Facebook) and publication of interesting contents into a web platform dedicated to LL.

All of these tools will serve as a mean for the public, as it is the mission of the LL.

Stakeholders' motivation is a wide management process which lasts for the entire operational phase of the LL. Keeping the motivation of stakeholders high is a key element for the success of the LL, because all the activities carried out are user-centered. Active and motivated users will be the key to ensure it. In this process the sponsorship by some strategic LL's partners will be determinant, for example, leading companies in the industrial sector, that sharing the mission of the LL will be able to maintain the motivation of traditional users high. In addition, it will be essential to promote relations with users constantly, activate new threads, respond quickly to feedback and questions, communicate clearly programs and objectives, organize meetings (virtual or not), share results, and so forth, until the user will feel part of the LL's community.

4.3. Commercialization Stage. The aim of this stage is the commercialization of product/service developed in the
KHIRA LL. This stage will occur only if there are the right conditions for the commercialization of a new product/ service, such as good business models, financial conditions or the creation of new startup that can allow the entry of a new product/service to market.

\section{Conclusion}

The KHIRA LL is a collaborative environment developed within the Collaborative Product Design Management (cPDM) Laboratory of the Centro Cultura Innovativa d'Impresa (University of Salento) operating according to the Living Labs approach that puts users in the middle of the innovation process, in order to develop new products/services in complex manufacturing environments.

The ability to innovate is one of the key objectives that the LL intends to pursue. According to Eriksson, Niitamo, and Kulkki's theory [18], there is a strong link between research and innovation, pursuant to which, it is appropriate to feed the innovation process with research activities.

Due to this approach an environment was created which enables the collaboration among different users categories: industrial partners, universities, research centers, manufacturing SMEs, public administrations, and others.

Currently, the KHIRA LL is in the planning phase in order to organize the operational context, both from the methodological and infrastructural points of view. In this regard, the research group involved has attempted to identify a suitable methodology to manage all the KHIRA LL activities able to meet a series of requirements.

This study has analysed the following methodologies: FormIT, SEE, C@R, and RIM highlighting two main trends: the methodological tendency to manage the innovation development process and the tendency to manage the organizational activities. In order to identify a methodology able to orchestrate an industrial LL in all its aspects, the KHIRA LL methodology has been proposed, bridging the existing gap between the LLs' activities management and those aimed to develop user-centered innovation. It is desirable, in the future, to apply the proposed methodology to the operational phase of the KHIRA LL, in order to identify potential problems and areas of improvement.

\section{Conflict of Interests}

The authors declare that there is no conflict of interests regarding the publication of this paper.

\section{References}

[1] J. Peppard and A. Rylander, "From value chain to value network: insights for mobile operators," European Management Journal, vol. 24, no. 2-3, pp. 128-141, 2006.

[2] V. Allee, "A value network approach for Modelling and Measuring Intangibles," 2002.

[3] R. Santoro and M. Conte, "Living Labs in Open Innovation Functional Regions," 2009, ESoCE-Net.

[4] ENoLL, "European Network of Living Lab," 2006, http://www .openlivinglabs.eu. 
[5] E. Almirall, "Living Labs and open innovation: roles and applicability," The Electronic Journal for Virtual Organizations and Networks, no. 10, pp. 21-26, 2008.

[6] P. Ballon, J. Pierson, and S. Delaere, Test and Experimentation Platforms for Broadband Innovation: Examining European Practice, Freie Universitat of Berlin.

[7] E. Von Hippe, "Users as innovators," in The Sources of Innovation, Oxford Press, London, UK, 1988.

[8] P. Markopoulos and G. Rauterberg, "Living Lab: a white paper," IPO Annual Progress Report, 2000.

[9] A. Corallo, M. E. Latino, M. Lazoi, S. Lettera, M. Marra, and S. Verardi, "Defining product lifecycle management: a journey across features, definitions, and concepts," Industrial Engineering, vol. 2013, 10 pages, 2013.

[10] J. C. Guzman, H. Schaffers, V. Bilicki, C. Merz, and M. Valenzuela, "Living Lab Fostering Open Innovation and Rural Development: Methodology and Results," 2009.

[11] K. B. Chen, H. L. Tsui, C. T. Yang, L. H. Ting, and H. Houng, A Living Lab Model for User Driven Innovation in Urban Communities, Institute for Information Industry, 2011.

[12] H. Schaffers and S. Kulkki, "An Open Innovation concept fostering rural developmentAsia-Pacific Tech Monitor," 2007.

[13] Rural Inclusion Living Lab, "Rural Incusion," 2009, http://www .rural-inclusion.eu/.

[14] A. Ståhlbröst and M. Host, The Living Lab Methodology Handbook, 2012.

[15] T. Keinonen and R. Takala, Product Concept Design: A Review of the Conceptual Design of Products in Industry, Springer, 2010.

[16] INCOSE, "Systems Engineering Vision 2020 INCOSE-TP2004-004-02," 2007.

[17] A. Osterwalder, "Business Model Generation. s.l.:Edizioni FAG," 2010.

[18] M. Eriksson, V. Niitamo, and S. Kulkki, "State-of-the-art in utilizing Living Labs approach to user-centric ICT innovationa European approach," 2005. 

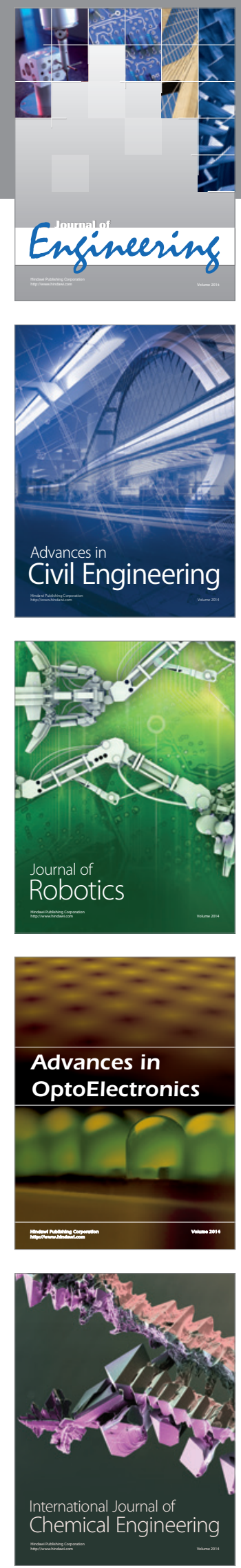

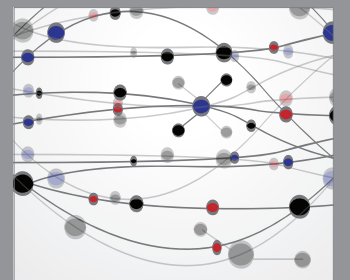

The Scientific World Journal
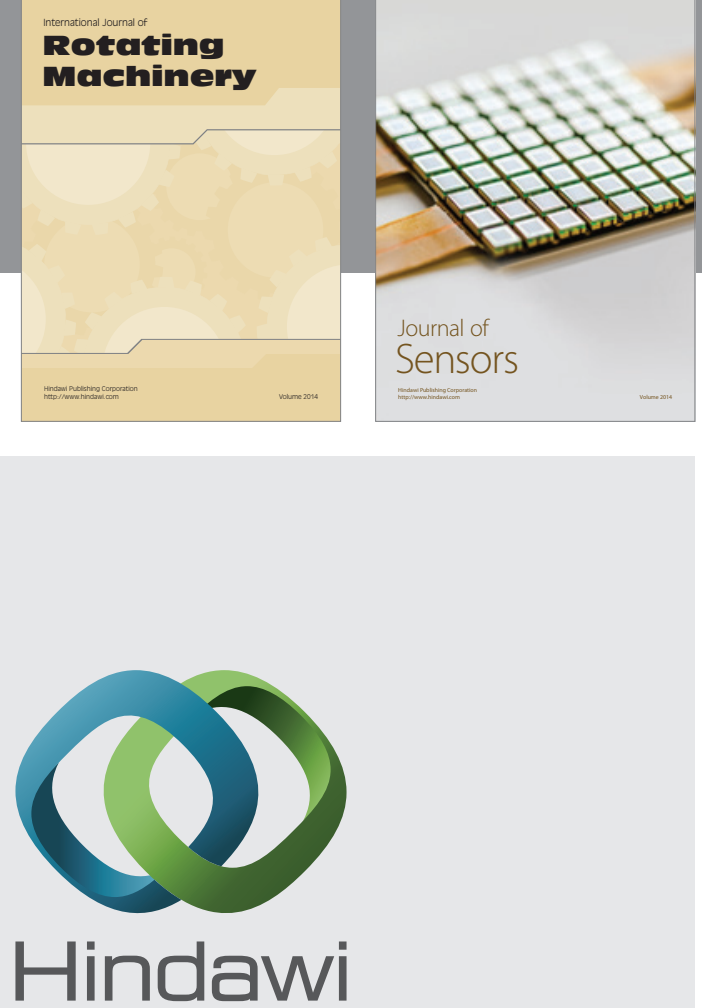

Submit your manuscripts at http://www.hindawi.com
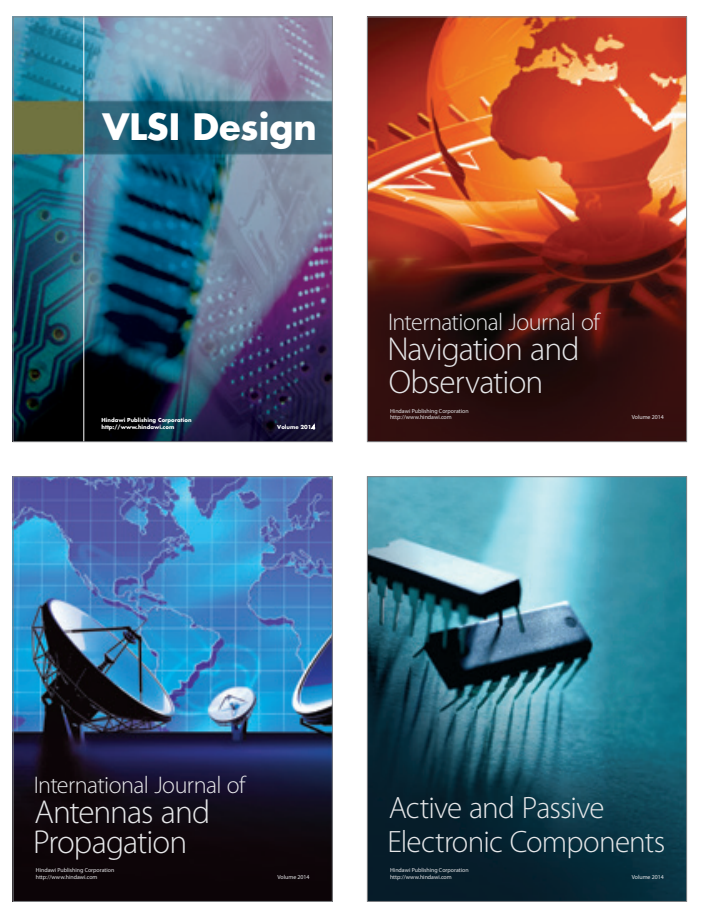
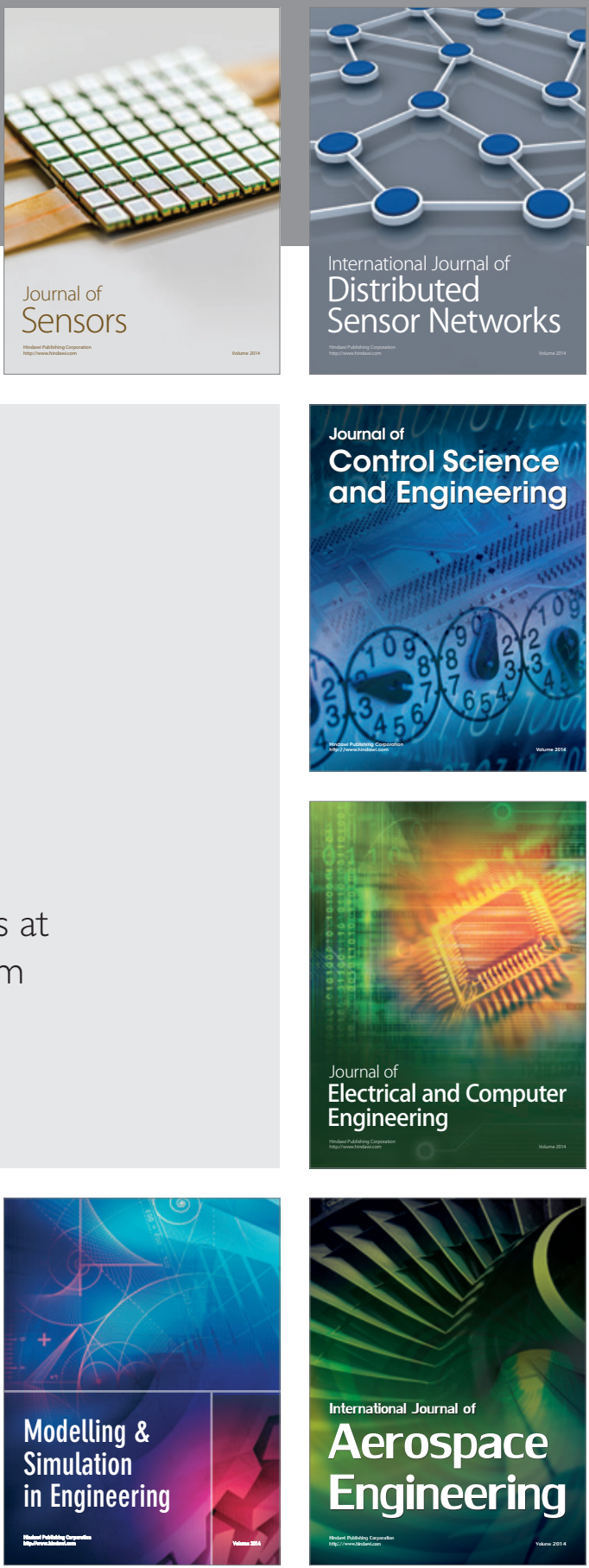

Journal of

Control Science

and Engineering
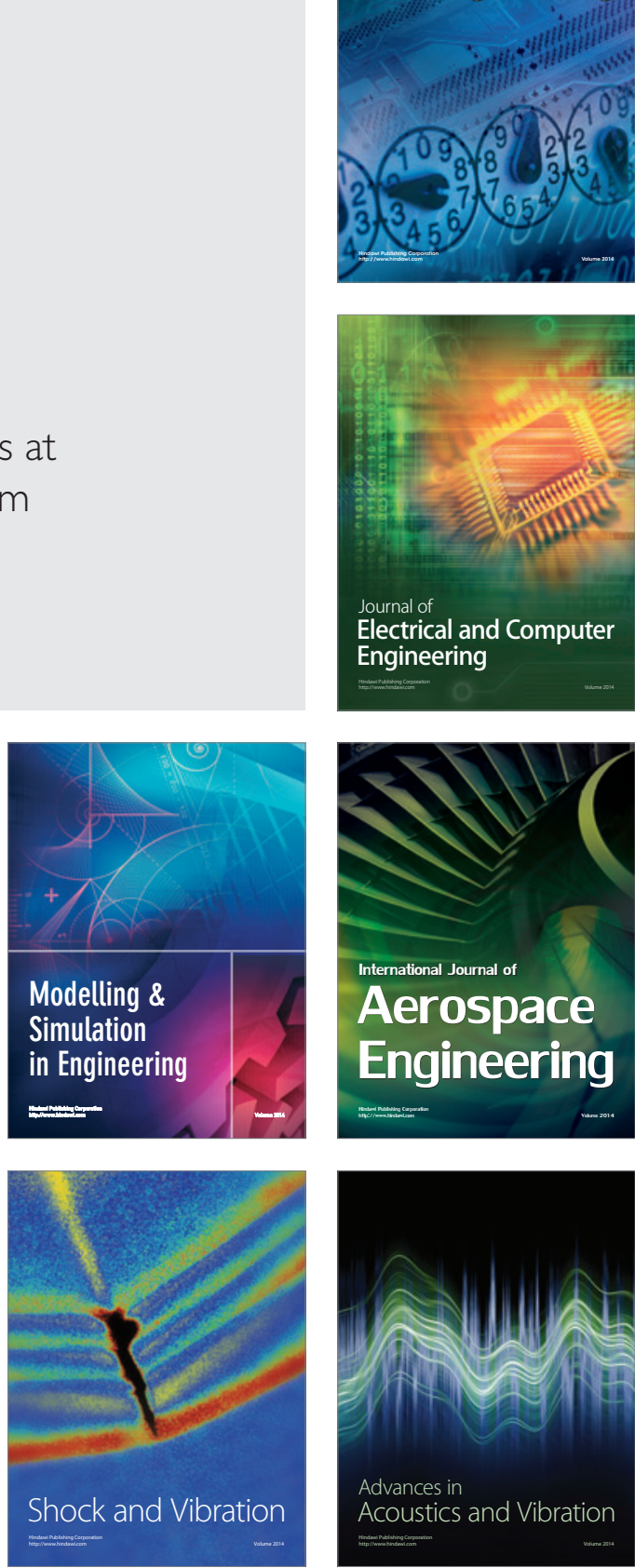